\title{
Genetic Diversity Analysis of Rice Cultivars Differing in Dormancy Based on SSR Markers
}

\author{
Sooganna $^{1,3^{*}}$, L.V. Subba Rao ${ }^{2}$, P. Kiranbabu ${ }^{4}$, K. Basavaraj ${ }^{2}$ and K. Keshavulu ${ }^{1}$ \\ ${ }^{1}$ Department of Seed Science and Technology, College of Agriculture, PJTSAU, \\ Hyderabad, India \\ ${ }^{2}$ ICAR- Indian Institute of Rice Research, Rajendranagar, Hyderabad, India \\ ${ }^{3}$ ICAR-Indian Institute of Millets Research, Rajendranagar, Hyderabad, India \\ ${ }^{4}$ Division of Plant Genetic Resources, ICAR-Indian Agricultural Research Institute, \\ New Delhi, India \\ *Corresponding author
}

\begin{abstract}
A B S T R A C T
Seed dormancy is an important trait affecting grain yield and quality in cereal crops. It is controlled by its own complicated genetic and environmental factors. The polymorphism

Keywords

Rice, Dormancy,

SSR markers,

Genetic diversity

Article Info

Accepted:

18 May 2019

Available Online:

10 June 2019 pattern study of 24 rice genotypes for RM primers used in the present molecular study were clearly classified the rice genotypes into dormant (Cluster I, Cluster IIA) and nondormant (Cluster II B, Cluster III). In the present study, a total of 40 alleles were detected across the 24 rice genotypes by 11 polymorphic SSR markers. The number of alleles generated per locus by each marker ranged from 2 to 6 . Maximum number of alleles (6) produced by RM 520. The PIC values among the SSR loci tested are ranged from 0.1411 (RM 480) to 0.7025 (RM 520) with an average of 0.495 per locus. Among the polymorphic SSR markers detected, RM 520 showed maximum numbers of alleles (6) as well as the highest PIC value (0.709). The markers showed average PIC value of 0.4954 that almost showed $49 \%$ polymorphism, which confirms that SSR markers used in this study were highly informative for genetic studies and are extremely useful in distinguishing the polymorphic rate of a marker at a specific locus.
\end{abstract}

\section{Introduction}

Dormancy enabled seeds to survive long periods of environmental conditions unfavorable for germination (Li et al., 2012). The seeds have evolved to postpone germination until a time and place that not only supports germination, but also maximizes seedling establishment and growth (Cao et al., 2014). Because dormant seeds don't germinate, dormancy was, for many years, considered to be some sort of seed defect or inactivity that meant that even a viable seed simply could not germinate (Garces et al., 2014; Mortensen and Grasser 2014; Tiwari et al., 2016). 
Seed dormancy is the transitory inability of a viable seed to germinate even under condition favourable for germination ( $\mathrm{Li}$ and Foley, 1997). It is an important stage of plant life cycle and a feature that is also useful in cultivated plants, as it can avoid pre-harvest sprouting (PHS) in the field conditions that are favourable for germination, such as warm and humid weather and the consequent poor grain quality and lower yield (Harlan et al., 1973). The degree of seed dormancy is affected by genetic factors controlling germination including the mechanical hardness of seed coats, the morphological or physiological immaturity of embryos and the activity of specific metabolic systems (Bewley, 1997; Baskin and Baskin 1998 and 2004; Bentsink et al., 2007). However, seed dormancy can be a disadvantage in plant breeding when it is necessary to sow successive generations as soon as possible after harvest so as to increase the number of selection rounds in a short period (Roberts, 1961). Dormancy is one of the traits among the cereal crops that have undergone domestication and could be a desirable trait as it can help prevent preharvest sprouting hence improved grain yield and quality (Harlen and de Wet, 1973; Gubler et al., 2005).

Dormancy in cereals seeds has been reported by several workers over the years (Das and sinha, 1965; Vaesey et al., 2004; Nirmala, 2006, Sooganna et al., 2012, Shiratsuchi et al., 2017). Recently a number of genetic studies on seed dormancy were carried out using molecular markers in various plant species such as rice (Seshu et al., 1986; Takahashi 1997; Wan et al., 1997; Dong et al., 2002; Miura et al., 2002; Gu et al., 2004; Kumar et al., 2009; Shiratsuchi et al., 2017), in barley (Oberthur et al., 1995; Larson et al., 1996; Prada et al., 2004), sorghum (Lijavetzky et al., 2000) and wheat (Anderson et al., 1993; Kulwal et al., 2004), and Arabidopsis (Schaar et al., 1997).
Microsatellites are tandem repeats of DNA sequences of only a few base pairs (1-6 bp) in length, the most abundant being the dinucleotide repeats (Morgante and Olivieri, 1992). Wu and Tanksley (1993) showed that simple sequence repeats such as $(\mathrm{GA})_{\mathrm{n}}$ and $(\mathrm{GT})_{\mathrm{n}}$ is not only present in the mammalian genome but also in rice genome. Yang et al., (1994) reported that because of the greater resolving power and the efficient production of massive amount of SSR data may be particularly useful for germplasm assessment and evolutionary studies of crop plants. SSRs have been characterized in many plant genomes such as rice, sorghum, maize etc.

A vast number of SSRs have been published in rice (Mc Couch et al., 2002) Because of their merits such as abundance, even genomic distribution and high level of polymorphism, SSRs are considered to be the markers of choice for DNA fingerprinting and genetic analysis studies.

Several major genes and Quantitative Trait Loci (QTL) controlling agronomically important traits have been mapped with tightly linked DNA markers in several crop species including rice, facilitating marker-assisted selection (MAS) for the traits. MAS have been successfully used in selecting for the trait of interest irrespective of the plant growth stage. Information on QTLs associated with dormancy would be of great help to the plant breeders so that this trait can be tailored in their breeding programmes in developing dormant and non-dormant rice varieties.

\section{Materials and Methods}

\section{Plant materials}

The experimental material consisted of 24 rice genotypes collected from ICAR-Indian Institute of Rice Research, Rajendranagar, Hyderabad, India (Table 1). 


\section{Genomic DNA isolation}

Extraction of bulk DNA was carried out by using maxiprep DNA isolation protocol described by Kumar et al., (2007) in rice crop. The purity and concentration of the isolated bulk DNA samples was estimated by UVabsorption spectrophotometer (Beckman DU 650 model) described. The ratio of absorbance at $260 \mathrm{~nm}$ and $280 \mathrm{~nm}$ was used as an indicator of DNA purity. The ratio between 1.4 and 1.9 was considered as relatively pure DNA samples as it did not show any effect on PCR reaction. The bulk genomic DNA concentration was measured by using the formula: DNA concentration in $\mu \mathrm{g} / \mu \mathrm{l}=\mathrm{OD}$ 260 x $50 \mu \mathrm{g}$ x dilution factor.

\section{Polymorphism survey through SSR markers}

The polymorphism survey was carried out with 11 SSR markers (Table 2). The PCR plate was labeled with respect to sample number and $2 \mu$ li.e. 50-100 ng) of template DNA was added to the respective wells. The master mix consisted of $0.5 \mu$ forward primer, $0.5 \mu \mathrm{l}$ reverse primer, $0.5 \mu \mathrm{l}$ dNTP's, $0.6 \mu \mathrm{l}$ Taq DNA polymerase (M/s Bangalore Genei Pvt. Ltd.), $1.0 \mu \mathrm{l}$ of $10 \mathrm{x}$ PCR buffer (Tris with $1.5 \mathrm{mM} \mathrm{Mg} \mathrm{Cl}$ ) and $4.9 \mu \mathrm{l}$ of sterile distilled water was added to make up the volume to $10 \mu \mathrm{l}$. Then the master mix $(8.0 \mu \mathrm{l})$ was dispensed to the PCR plate with template DNA. The PCR plate was covered with a sealing mat. It was then placed in a programmable thermal cycle (M/s Applied Biosystem, USA) for DNA amplification.

The thermal cycling programme is as follows: initial denaturation of $94{ }^{\circ} \mathrm{C}$ for $5 \mathrm{~min}, 35$ cycles of denaturation at $94{ }^{\circ} \mathrm{C}$ for $30 \mathrm{sec}$, annealing at $55^{\circ} \mathrm{C}$ for $30 \mathrm{sec}$, and extension at $72{ }^{\circ} \mathrm{C}$ for $1 \mathrm{~min}$, followed by final extension at $72{ }^{\circ} \mathrm{C}$ for $7 \mathrm{~min}$ and hold at $4{ }^{\circ} \mathrm{C}$.
After completion of the PCR, the plate was stored at $-20^{\circ} \mathrm{C}$ and later checked for amplification on a $3 \%$ agarose gel stained with Ethidium bromide. The PCR products were checked for amplification by electrophoresis using a $3 \%$ agarose gel (M/s SeaKem LE Agarose, Lonza, USA) in a Submarine Horizontal Electrophoresis Unit (M/S. Biorad, USA). About $10.5 \mathrm{~g}$ of agarose was weighed and transferred into a reagent bottle containing $350 \mathrm{ml}$ of $0.5 \mathrm{X}$ TBE (Tris-borate EDTA) buffer and mixed well. The content was then boiled gently in a microwave oven with intermittent mixing. The process was followed until agarose melts completely and the solution becomes clear. In the meanwhile, the gel-casting tray was washed with water and wiped with ethanol. Then it was sealed with cello tape. The agarose gel solution was cooled down to bearable heat $\left(\sim 40^{\circ} \mathrm{C}\right)$ and 18 $\mu \mathrm{l}$ of ethidium bromide $(10 \mathrm{mg} / \mathrm{ml})$ was added to it.

The content was mixed thoroughly and poured into the gel-casting tray where the combs were arranged in the slots on the gel-casting tray. The gel was allowed to solidify at room temperature for 20-30 min. Care was taken so that no air bubble was present. Later the gel was transferred to a Submarine Horizontal Electrophoresis Unit containing $0.5 \chi \mathrm{TBE}$ buffer. Before loading, amplified products were mixed with $1 / 6^{\text {th }}$ volume of gel loading dye ( $40 \%$ sucrose; $0.25 \%$ bromophenol blue) and loaded into the wells with help of micro tips.

The electrodes were connected to power pack and samples were run at $120 \mathrm{~V}$ for $1 \mathrm{hr} .100$ bp ladder (Fermentas Generuler - $0.1 \mu \mathrm{g} / \mu \mathrm{l}$ ) was loaded in first well to determine the size of amplified fragments. The amplicons were visualized under UV-transilluminator and documented using ALPHA IMAGER gel documentation system (M/s. Alpha Innotech). 


\section{Statistical analyses}

For each SSR marker, the total number of alleles were noted and the allelic status was converted in to binary $(0,1)$ data. 'Polymorphism information content' (PIC) was determined as described by Senior et al., (1998). PIC is a measure of allele diversity at a locus and is equal to $1-\Sigma\left(\mathrm{P}_{\mathrm{ij}}{ }^{2}\right)$, where $\mathrm{P}_{\mathrm{ij}}$ is the frequency of $\mathrm{j}^{\text {th }}$ allele for $\mathrm{i}^{\text {th }}$ locus summed across all alleles in the locus. PIC is synonymous with the term "gene diversity" as described by Weir (1996).

The PIC values ranging from ' 0 ' (monomorphic) to ' 1 ' (very highly discriminative, with many alleles in equal frequencies) provide an estimate of the discriminatory power of a marker by taking into account not only the number of alleles at locus, but also the relative frequencies of those alleles in the genotypes under study. For example, a marker locus that reveals five alleles, but where one allele is found in very high frequency (for example, freq. $=0.9$ ), has overall less discriminative capability than a locus that also has five alleles, but in which those alleles are found in more equal frequencies.

Mean PIC value was calculated based on PCR values obtained across various SSRs loci, excluding a few primers that revealed a higher frequency of nulls, as latter could inflate the PIC value.

\section{Cluster analysis}

The clustering of accessions was done by using Numerical Taxonomy and Multivariate Analysis System (NTSYSpc. Rohlf, 1998) based on a similarity matrix using an Un weighted Pair Group Method with Arithmetic average (UPGMA) algorithm following Sequential Agglomerative Hierarchical and Nested (SAHN) module.

\section{Results and Discussion}

\section{Number of alleles}

In the present study, a total of 40 alleles were detected across the 24 rice genotypes by 11 polymorphic SSR markers. The number of alleles generated per locus by each marker ranged from 2 to 6 . Maximum number of alleles (6) produced by RM 520. In the present study, the PIC values among the SSR loci tested are ranged from 0.1411 (RM 480) to 0.7025 (RM 520) with an average of 0.4954 per locus. Among the polymorphic SSR markers detected, RM 520 showed maximum numbers of alleles (6) as well as the highest PIC value (0.7095). The amplification profiles of polymorphic SSR markers are given in the Figure 1. Polymorphism information content (PIC) value is the reflection of allele diversity and frequency among the genotypes. To measure the informativeness of each SSR marker, PIC value was calculated. The PIC value is the indicator in predicting the usefulness of DNA markers for gene mapping, molecular breeding and germplasm evaluation. Markers with higher PIC values possess greater potential to reveal allelic variation. The average PIC value of SSR markers of different crops tested by different researchers varied based on number of SSR markers used and number of genotypes tested. The markers showed average PIC value of 0.4954 that almost showed 49\% polymorphism, which confirms that SSR markers used in this study were highly informative for genetic studies and are extremely useful in distinguishing the polymorphic rate of a marker at a specific locus.

\section{Cluster analysis}

The cluster analysis resolved the 24 rice genotypes into three major clusters at $0.72 \%$ similarity. Dendrogram based on UPGMA 
analysis grouped the 24 genotypes into three clusters. Cluster I divided at 0.70 similarity coefficient consists of only one genotype (MTU2077) which is dormant and cluster II consists of both dormant and non-dormant genotypes and cluster III is the major one consists of 17 non-dormant genotypes.

Table.1 List of rice genotypes and seed dormancy status

\begin{tabular}{|c|c|}
\hline Varieties & Trait \\
\hline Mandyavijaya & Non-dormant \\
\hline Manasarovar & Non-dormant \\
\hline Akshayadhan & Non-dormant \\
\hline RP Bio-226 & Non-dormant \\
\hline Suraksha & Non-dormant \\
\hline Sampada & Non-dormant \\
\hline Mahasuri & Non-dormant \\
\hline Vikramarya & Non-dormant \\
\hline Swarnadhan & Non-dormant \\
\hline Phalguna & Non-dormant \\
\hline Dhanarasi & Non-dormant \\
\hline Varadhan & Non-dormant \\
\hline Mugadhasugandha & Non-dormant \\
\hline DRR Dhan 38 & Non-dormant \\
\hline Jaya & Non-dormant \\
\hline Sugandhamati & Non-dormant \\
\hline Sona & Non-dormant \\
\hline Sonasali & Non-dormant \\
\hline DRR Dhan 39 & Non-dormant \\
\hline Jarava & Non-dormant \\
\hline MTU1001 & Dormant \\
\hline MTU2067 & Dormant \\
\hline MTU2077 & Dormant \\
\hline Jeerakasala & Dormant \\
\hline
\end{tabular}


Table.2 Number of alleles and Polymorphism information content (PIC) values of 11 SSR markers

\begin{tabular}{|c|c|c|c|c|c|}
\hline MARKER & FORWARD PRIMER SEQUENCE & REVERSE PRIMER SEQUENCE & $\begin{array}{l}\text { NUMBER } \\
\text { OF } \\
\text { ALLELES }\end{array}$ & PIC & HETEROZYGOSITY \\
\hline RM 346 & CGAGAGAGCCCATAACTACG & ACAAGACGACGAGGAGGGAC & 4 & 0.6142 & 0.6759 \\
\hline RM 237 & CAAATCCCGACTGCTGTCC & TGGGAAGAGAGCACTACAGC & 2 & 0.3318 & 0.42 \\
\hline RM 271 & TCAGATCTACAATTCCATCC & TCGGTGAGACCTAGAGAGCC & 2 & 0.2859 & 0.3457 \\
\hline RM 520 & AGGAGCAAGAAAAGTTCCCC & GCCAATGTGTGACGCAATAG & 6 & 0.7025 & 0.74 \\
\hline RM 564B & CATGGCCTTGTGTATGCATC & ATGCAGAGGATTGGCTTGAG & 5 & 0.6707 & 0.7143 \\
\hline RM 164 & TCTTGCCCGTCACTGCAGATATCC & GCAGCCCTAATGCTACAATTCTTC & 4 & 0.5806 & 0.6281 \\
\hline RM 3602 & TGAAAAGCCACTCAGATGCG & TGGTGAAAGGGTCAGAACTG & 5 & 0.5396 & 0.6 \\
\hline RM 231 & CCAGATTATTTCCTGAGGTC & CACTTGCATAGTTCTGCATTG & 4 & 0.6506 & 0.7072 \\
\hline RM 480 & GCTCAAGCATTCTGCAGTTG & GCGCTTCTGCTTATTGGAAG & 2 & 0.1411 & 0.1528 \\
\hline RM 234 & ACAGTATCCAAGGCCCTGG & CACGTGAGACAAAGACGGAG & 3 & 0.4898 & 0.5805 \\
\hline RM 421 & AGCTCAGGTGAAACATCCAC & ATCCAGAATCCATTGACCCC & 3 & 0.4427 & 0.4965 \\
\hline
\end{tabular}


Figure.1 Amplification profiles of RM421, RM234, RM231 and RM 480 SSR primers from 24 rice genotypes. Lane 1 is 100 bp ladder
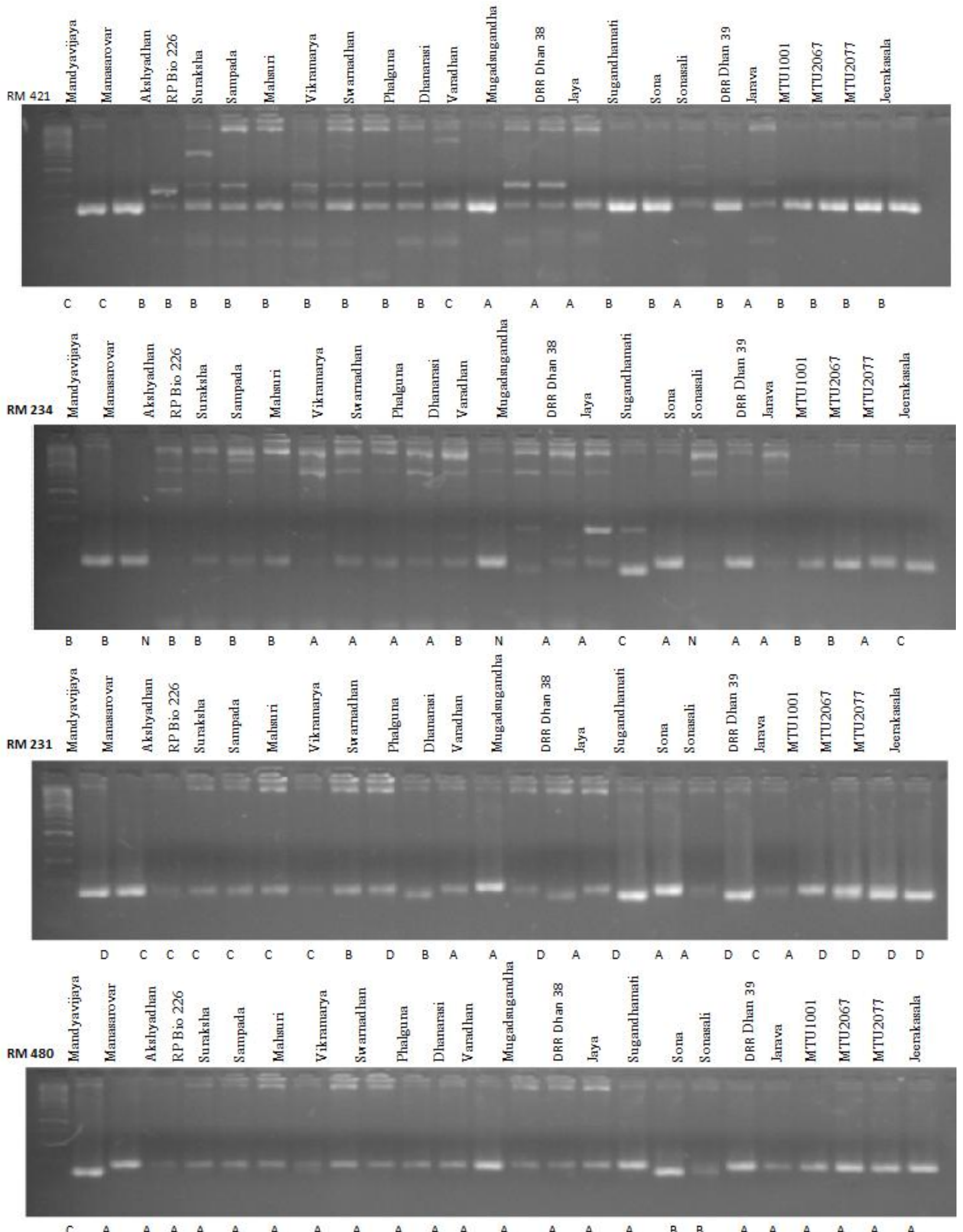
Figure.2 Dendrogram based on UPGMA analysis grouped the 24 rice genotypes

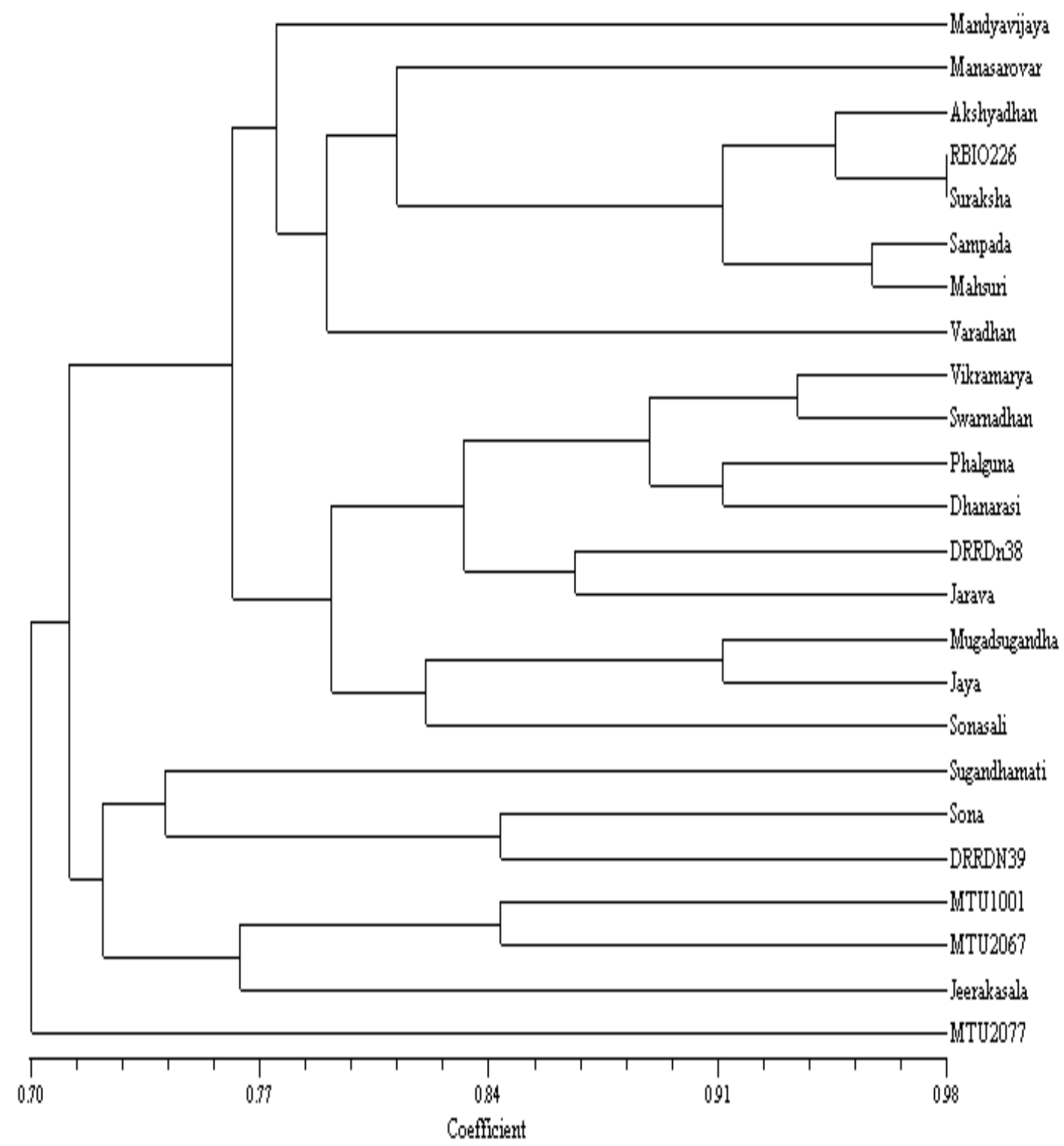

The cluster II was divided into two sub clusters, cluster II-A and cluster II-B at similarity coefficient 0.76 and 0.73 respectively. The cluster II-A consists of three genotypes which are dormant in nature and cluster II-B consists of three genotypes which are non-dormant. The cluster III is the major one consisting of 17 genotypes which are non-dormant. It was divided in to three sub clusters viz., Cluster III-A, cluster III-B and cluster III-C at similarity coefficient 0.81 , 0.83 and 0.77 respectively (Fig. 2).

The primers used in the present study were clearly classified the genotypes into dormant and non-dormant. The similar results were reported by Heng Ye et al., (2011) for primers. RM 3602 was linked with the qSdn-1 on chromosome 1. RM 520, RM 164 were linked with qSdn-3, qSdn-5 respectively. 
Similarly RM 234, RM346 were also linked with qSdn-7 on chromosome 7. The primer RM 480 was linked with the qSdn-5 on chromosome $5 \mathrm{Lu}$ et al., (2011). The similar findings were also reported by Langbiao Guo et al., (2004) that RM 237 and RM 164 were associated with qSdn-1 and qSdn-5 respectively.

\section{Acknowledgement}

I acknowledge ICAR- Indian Institute of Rice Research, Rajendranagar, Hyderabad, India for providing me the opportunity.

\section{References}

Anderson J.A., Sorrells, M. E. and Tanksley S. D. 1993. RFLP analysis of genomic regions associated with resistance to preharvest sprouting in wheat. Crop Sci., 33:453-459.

Baskin C. C. and Baskin J. M. 1998. Seeds: ecology, biogeography, and evolution of dormancy and germination. San Diego: Academic.

Baskin J. M. and Baskin C.C. 2004. Classification system for seed dormancy. Seed Sci. Res., 14:1-16.

Bentsink L., Soppe W. and Koornneef M. 2007. Genetic aspects of seed dormancy. In: Bradford K, J; Nonogaki, $\mathrm{H}$ (eds) Seed development, dormancy and germination. Blackwell, Oxford, 264-304.

Bewley J D. 1997. Seed germination and dormancy. Plant Cell, 9: 1055-1066.

Chengdao L., Peixiang N., Michael F., Adam H., Yong Z., David S., Heng L., Allen T., Jun W., Mehmet C., Jun Y., Matthew B., Reg L., and Rudi A., 2004. Genes controlling seed dormancy and pre harvest sprouting in a rice-wheatbarley comparison. Funct Integr Genom, 4: 84-93.

Dong Y, Tsozuki E, Kamiuten H, Terao H,
Lin D, Mastuo M. 2002. Identification of qualitative trait loci associated with pre-harvest sprouting in rice (Oryza sativa L.). Field Crop Res, 81: 133-139.

Garces H.M.P., Koenig D., Townsley. B.T., Kim, M.S. and Sinha N.R. 2014. Truncation of leafy cotyledon protein is required for asexual reproduction in Kalanchoe daigremontiana. Plant Physiology, 165: 196-206.

Gu X.Y., Liu T., Feng J., Suttle J.C., and Gibbons J. 2010. The qSD12 underlying gene promotes abscisic acid accumulation in early developing seeds to induce primary dormancy in rice. Plant Mol. Biol., 73:97-104.

Gu X.Y., Kianian S.F., and Foley M.E. 2004. Multiple loci and epitasis control genetic variation for seed dormancy in weedy rice (Oryza sativa). Genetics, 166: 1503-1516.

Gubler F, Millar A A, Jacobsen J V. 2005. Dormancy release, ABA and preharvest sprouting. Curr. Opin. Plant Biol., 8: 183-7.

Harlan J.R., De Wet J. M. J, and Price E.G. 1973. Comparative evolution of cereals. Evolution, 27:311-325.

Heng Y.E., Michael E., Foley, Xing, You G.U. 2010. New seed dormancy loci detected from weedy rice-derived advanced populations with major QTL alleles removed from the background. Plant Sci., 179: 612619.http://www.gramene.org/qtl/index.h tml

Kulwal P.L., Singh R., Balayan H.S, and Gupta P.K. 2004. Genetic basis of preharvest sprouting tolerance using single locus and double locus QTL analysis in bread wheat. Funct. Integr. Genomics, 4: 94-101.

Kumar M., Rajpurohit D., Basha P.O.A., Bhalla A., Randhawa G.S., and Dhaliwal H.S. 2009. Genetic Control of Seed Dormancy in Basmati Rice. 
Madras Agric. J., 96 (7-12): 305-308.

Kumar R.P., Sujatha K., Rao K.S., Nataraj K. P., Viraktamath B.C., Balchandran S.M., Biswal A.K., and Sundaram R.M. 2007. A protocol for isolation of DNA suitable for rapid seed and grain purity assessments in rice. Rice Genet., 23: 9295.

Langbiao G., Lihuang Z., Yunbi X., Dali Z., Ping W., Qian. 2004. QTL analysis of seed dormancy in rice (Oryza sativa L.). Euphytica 140: 155-162.

Larson, S., Bryan G., Dyer W., and Blake T. 1996. Evaluating gene effects of a major barley seed dormancy QTL in reciprocal backcross populations. $J$. Quant. Trait Loci., 2: Article 4

Li, B. and Foley M.E. 1997. Genetic and molecular control of SD. Trends Plant Sci., 2:384-389.

Li, X.H., Jiang D.M., Alamusa, Z., Lai, Q. and Oshida, T. 2012. Comparison of seed germination of four Artemisia species (Asteraceae) in northeastern Inner Mongolia China. Journal of Arid Land, 4: 36-42.

Lijavetzky, D., Martinez, M.C., Carrari, F., Hopp, and H.E. 2000. QTL analysis and mapping of pre-harvest sprouting resistance in sorghum. Euphytica, 112: 125-135.

Lu. B., Kun xie., Chunyan yang., Songfeng wang., $\mathrm{Xi}$ Liu., Longzhang., Ling Jiang., and Jianmin Wan. 2011. Mapping two major effect grain dormancy QTL in rice. Mol. Breed., 28:453-462.

Magwa, R.A., Zhao, H., and Xing, Y. 2016. Genome-wide association mapping revealed a diverse genetic basis of seed dormancy across subpopulations in rice (Oryza sativa L.). BMC Genetics, 17:28

Mccouch, S.R., Teytelman, L., Xu, Y., Lobos, K.B., Clare, K., Walton, M., Fu, B., Maghirang, R., Li, Z., Xing, Y., Zhang, Q., Kono, I., Yano, M., Jelstrom, R.F.,
Declerck, G., Schneider, D., Cartinhour, S., Ware, D., and Stein, L. 2002. Development and Mapping of 2240 New SSR Marker of Rice (Oryza sativa L.). DNA Res., 9:199-207.

Miura, K., Lin, S.Y, Yano, M. and Nagamine T. 2002. Mapping quantitative trait loci controlling seed longetivity in rice (Oryza sativa). Theor. Appl. Genet., 104: 981-986.

Morgante, M. and Olivieri. A.M. 1992. PCR amplified microsatellites as marker in plant genetics. Technical Advance, 175182.

Mortensen, S.A. and Grasser K.D. 2014. The seed dormancy defect of Arabidopsis mutants lacking the transcript elongation factor TFIIS is caused by reduced expression of the DOG1 gene. FEBS Letters, 588: 47-51.

Oberthur, L., Blake, T.K., Dyer, W.E. and Ulllrich S.E. 1995. Genetic analysis of seed dormancy in barley (Hordeum vulgare L.). J Quant Trait Loci 1: Article 5

Prada, D., Ullrich. S.E., Molina-Cano, J.L., Cistue, L., Clancy, J.A. and Romogosa, I. 2004. Genetic control of dormancy in a Triumph/Morex cross in barley. Theor. Appl. Genet., 109: 62-70.

Rathi, S., Baruah, A.R., Chowdury, R.K. and Sarma R.N. 2011. QTL Analysis of seed dormancy in indigenous rice of Assam, India. Cereal Res. Commun., 39(1):137-146.

Roberts, E H. 1961. Dormancy of rice seed. The distribution of dormancy periods. $J$. Exp. Bot., 13:319-339.

Rohlf, F.J. 1998. NTSYS-pc numerical taxonomy and multivariate analysis system. Version 2.02. Exeter Publications Setauket, New York.

Saghai Maroof, M.A., Yang, G.P., Zhang, Q. and Gravois, K.A. 1994. Correlation between molecular marker distance and hybrid performance in U.S. Southern 
long grain rice. Crop Sci., 37: 145150

Schaar W, van der., Alonso-Blanco C., Leonkloosterzil, K.M., Jansen, R.C., van Ooijen, J.W. and Koornneef M. 1997. QTL analysis of seed dormancy in Arabidopsis using recombinant inbred lines and MQM mapping. Heredity, 79:190-200.

Senior, M.L., Murphy, J.P., Goodman, M.M. and Stuber, C.W. 1998. Utility of SSRs for determining genetic similarities and relationships in maize using an agarose gel system. Crop Sci., 38: 1088-1098.

Seshu, D.V., Sorrells, M.E. 1986. Genetic studies on seed dormancy in rice. In: Rice Genetics I. IRRI, Manila, Philippines. Pp 369-382.

Shiratusuchi, H., Ohdaria, Y., Yamaguchi, H. and Fukuda, A. 2017. Breaking the dormancy of rice seeds with various dormancy levels using steam and high temperature treatments in a steam nursery cabinet. Plant Production Science, 20 (10): 183-192.

Sneath, P.H.A. and Sokal R.R. 1973. Numerical Taxonomy. W.H. Freeman Ed. San Fransisco. 573.

Sooganna, Rao, L.V.S., Babu, P.K., Chaitanya, U. and Keshavulu, K. 2012. Effect of maleic hydrazide on induction of seed dormancy and seed quality parameters in rice. Seed Res., 40(2): 124-133.

Takahashi N. 1997. Inheritance of seed germination and dormancy. In: Science of rice plant. 3. Genetics. food and Agric Policy Res Center, Tokyo, pp 348-359

Tiwari, A.K., Tiwari, T.N. and Prasad, S.R. 2016. Seed dormancy in ornamental plants: A review. Ind. J. Agri. Sci., 86 (5): 580-92

Veasey, E.A., Karasawa, M.G.M., Santos, P.P., Rosa, M.S., Mamanie, E. and Oliveira, G.C.X. 2004. Variation in the loss of seed dormancy during afterripening of wild and cultivated Rice Species. Ann. Bot., 94:875-82.

Wan, J., Nakazaki, T., Kawaura, K. and Ikehashi, H. 1997. Identification of marker loci for seed dormancy in rice (Oryza sativa L.). Crop Sci., 37:17591763.

Wu, K.S. and Tanksley, S.D. 1993. Abundance, polymorphism and genetic mapping of micro satellites in rice. Moecular Genet., 241: 225-235.

Xie, K., Jiang Ling., Lu B., Yang C., Li L., Liu X., Zhang, L., Zhao Z. and Wan J. 2011. Identification of QTLs for seed dormancy in rice (Oryza sativa L.) Plant Breeding, 130(3): 328-332.

Yang, G.P., Saghai, M.A., Maroof, Xu, C.G., Zhang, Q. and Biyashev, R.M. 1994. Comparative analysis of microsatellite DNA polymorphisms in land races and cultivars of rice. Molecular Genet., 245: 187-194.

\section{How to cite this article:}

Sooganna, L.V. Subba Rao, P. Kiranbabu, K. Basavaraj and Keshavulu, K. 2019. Genetic Diversity Analysis of Rice Cultivars Differing in Dormancy Based on SSR Markers. Int.J.Curr.Microbiol.App.Sci. 8(06): 3289-3299. doi: https://doi.org/10.20546/ijcmas.2019.806.392 